


\title{
10 investigación parteras y/o comadronas: "Prácticas culturales y sociales de las mujeres rurales-chortí en torno a la fertilidad y reproducción" Estudio de caso en Copán Ruinas
}

\author{
M sc. Zoila Madrid Rossell y Dra. Delmi Castillo
}

\section{INTRODUCCIÓN}

Los Derechos sobre el cuerpo y la decisión sobre la reproducción y la salud reproductiva de las mujeres indígenas muy poco ha sido estudiada, y por lo tanto no ha sido consignada específicamente en las Declaraciones Internacionales sobre la mujer y de población.

Para remediar esta situación de marginalidad hay que garantizar que las mujeres in dígenas gocen de los mismosderechos normados para todas las mujeres en el contexto exacto de sus prácticas culturales y su cosmovisión, que primero es necesario indagar.

El plantear investigar mujer y reproducción de las mujeres chortí, es una relación que tiende a profundizar y rescatar las prácticas de salud tradicional de las mujeres con las prácticas médicas alópatas, buscar los puntos de intersección y de separación.

La elección del tema obedeció al interés de reflexionar que sobre como la atención a salud hacia las mujeres se realiza por parte de la medicina moderna; donde el conocimiento sobre salud heredado ancestral mentea las mujeres es desconocido, negado y juzgado como mala práctica, y develar un conocimiento no valorado e invisi bilizado.

En el país la mayoría de estudios sobre las prácticas reproductivas de las mujeres se realizan a nivel macro sin considerar la heterogeneidad de la población. Es por eso que:

* Los programas de Salud Sexual y R eproductiva son diseñados y dirigidos en forma estan darizada sin considerar la heterogeneidad y las especificidades de identidades femeninas que los rasgos específicos de raza y pobreza connotan.

* Conocer las percepciones y prácticas culturales al rededor de la fecundidad en el grupo específico de mujeres maya-chorti a través de las parteras, nos proporciona pistas sobre cómo interrelacionar prácticas y actitudes modernas con prácticas tradicionales.

Las/os actores que intervienen en las prácticas de fecundidad tienen percepciones e intereses diferentes, los identificados son: el
M inisterio de Salud Pública a través del Centro de Salud de la Zona, las parteras tradicionales, Las parteras profesionalizadas y las mujeres de la Zona, es importante conocer cómo se interceptan prácticas modernas con tradicionales para definir con mayor claridad políticas y estrategias de trabajo con mujeres.

\section{PROPÓSITO DEL ESTUDIO}

La investigación contiene dos elementos básicos, el rol de las mujeres en sus prácticas culturales tradicionales y el uso de plantas medicinales o "remedioscaseros" en la atención y prevención de situaciones de salud reproductiva, principalmente la atención en mujeres embarazadasy en el parto.

Este trabajo permite contrastar el sincretismo en dos concepciones y representaciones sobre salud y enfermedad, la indígena y la mestiza.

Prácticas en su mayoría desconocidas, debido a que H onduras históricamente es un país con un desarrollo orientado al denominado corredor central, donde se concentran los servicios de salud y otros; las zonas postergadas como en el caso de las indígenas han estado en manos de curanderas y parteras locales. Con las políticas de población existen programas descentralizadas para la atención en la reproducción, éstos no han recibido la aceptación esperada, aunque en el discurso es "aceptado", las mujeres se resisten a su práctica.

En H onduras el sistema de salud ha centralizado la atención a las mujeres en las principales zonas urbanas del país. Existen en los lugares más postergados existen los centros de salud la mayoría de ellos a cargo de una enfermera. El Centro de Salud cuenta con médico permanente es de reciente data, fue hasta 1987 que se integró el CESA M O. A nterior a esto, la salud de las mujeres estaba bajo responsabilidad de parteras y curan deras de la zona, y en casos de gravedad tenían que trasladarse hasta la Ciudad de Santa Rosa de C opán.

Las políticas impulsadas por el Estado y los O rganismos $\mathrm{No}$ gubernamentales en lo referente a la Salud Sexual y Reproductiva 
delas mujeres, generalmente no logran los impactos propuestos, producto del desconocimiento de las particularidades culturales que existen en grupos específicos de mujeres como las indígenas, caso maya-chorti, Copán Ruinas.

\section{El estudio se planteó como objetivos:}

1. Recuperación de las prácticas culturales de parteras rurales con énfasis en la población chorti en relación a la salud reproductiva con el fin de identificar sus percepciones sobre la fecundidad y reproducción.

2. Identificar las principales remedios caseros y plantas medicinales usadas durante el embarazo, parto, post-parto y aborto.

\section{METODOLOGÍA}

El estudio sobre percepciones y practicas cultural es en relación a la fecundidad y reproducción, requirió de la utilización de técnicas cual itativas por medio de ellas se logró obtener ideas, representaciones, creencias y prácticas de salud tradicionales.

Estas modalidades metodológicas, permitan darnos cuenta de la subjetividad, de las creencias, valores, motivaciones de las mujeres, se utilizaron como técnicas el grupo focal y la entrevista a profundidad.

Para desarrollar los grupos focales se seleccionaron mujeres parteras de diferentes aldeas, priorizando las de población Chorti. Participaron en el grupo mujeres indígenas y mestizas. De ellas se eligió una partera para la entrevista a profundidad, la selección se realizó con los criterios siguientes: que sea indígena, con una práctica de más de 10 años.

Previo a abordar el tema de prácticas y percepciones se realizó una primera fase diagnóstica sobre la fecundidad y natalidad, recuperando las estadísticas que registra el centro de salud de la zona, donde la mortalidad materna del municipio asciende a 386 muertes por cada 100,000 nacida/os viva/os, índice superior del promedio nacional que para el año 2002 ascendió a 108 muertes.

El estudio consideró como prácticas culturales de salud a:

- Tipo de atención

- Tipo de dietas alimenticias

- Tipo de rutinas

- Tipos de medicina natural

- Creencias sobrenaturales

En el análisis se responde a interrogantes principales cómo:

1. ¿C uál el la cosmovisión que las mujeres y las parteras tien en sobre la fecundidad?

2. ¿C uáles son las prácticas tradicionales y modernas alrededor de la maternidad -embarazo, parto y lactancia.

3. ¿C uáles son las percepciones sobre la maternidad de las mujeres?

4. ¿C uáles son las interrelaciones entre las diferentes actoras en torno a la maternidad y la reproducción?
HIPÓTESIS

\section{La investigación se planteó las siguientes hipótesis}

1. Las prácticas culturales tradicionales de las mujeres mayachortí difieren de las prácticas modernas en torno a la fecundidad y salud reproductiva.

2. La identidad de género basada en la maternidad con las intercepciones de raza y clase es un punto referencial para la interrelación entre las/os diferentes actores.

Las variables género/etnicidad definen identidades particulares y percepciones diferenciadas sobre la fecun didad, que es necesario conocer para orientar adecuadamente los proyectos que buscan beneficiar a estas indígenas. Las problemáticas de las mujeres son trabajadas general mente sin los cuidados necesarios para poder realizar prácticas de interrelación y de reconocimiento de los mismoso de ellas.

N os interesó identificar las percepciones y prácticas cultural es de las mujeres parteras maya-chorti.

H istóricamente en la tradición maya- chorti la partera ha representado una papel privilegiado, en el libro sagrado de los M ayasQ uiches, la partera ocupa un Iugar privilegiado:

"-Averiguar por nuestra gente construída, gente formada, que nos invoquen, que nos den prioridad. $Q$ ue entrares en oración partera, ancestro, nuestra abuela, nuestro abuelo..." (PopWuj.Pag. 6)

Las prácticas culturales denotan la cosmovisión que existe en las comunidades maya-chorti sobre los aspectos de la reproducción humana, Rocio Tábora cita a A dalid M artinez, 1 en lo referente a las prácticasque comprometen la calidad de vida de las mujeres mayachortís:

"La pubertad se presenta entre las mujeres a los doce o trece años y a los trece o catorce entre los varones y desde entonces se les considera aptos para el matrimonio(...) Esta costumbre está tan arraigada en la comunidad de $\mathrm{C}$ honcó que incluso existe una curandera que cuando la muchacha pasa los quince años y no se ha casado, o estando casada no ha concebido hijo, le hace un baño de hierbas que la excita al matrimonio la condiciona para concebir" (...) una ley muy impresionante en la que el C hortí considera de muy mal agüero o desgracia que la mujer sea estéril, por lo que el indígena puede apalear a su mujer por el hecho de no poder parir. A unque la pareja acuda al Shamán para que trate de lograr la fecundación con promesas al santo (anualito), medicinas y presente (sacrificio de animales), mientras la cura se hace realidad el marido apalea a

\section{la mujer o la castiga moralmente"}

La anterior descripción nos da cuenta de la importancia de la fecundidad en la etnia chortí y la respon sabilidad exclusiva que recae sobre la vida de las mujeres y denota el control sobre la reproducción y la sexualidad en una relación de poder por parte de los hombres.

La violencia hacia las mujeres por parte de los hombres es la demostración clara de las relaciones de injusticia de género.

Por lo anterior es necesario en el estudio sobre las mujeres y la 
reproducción necesita de lecturas desde una perspectiva de género citando a Scott(1991) expresa:

". . el género es un elemento constitutivo de las relaciones sociales basadas en las diferencias percibidas entre los sexos, y el género es la forma primera de significar las relaciones de poder". El género es una categoría conceptual que permite el análisis de la complejidad de la reproducción y fecundidad en cosmovisiones etnoculturales.

Las prácticas sociales responden en la mayoría de los casos a mitos cultural es que es necesario acercarse en el estudio, .." De una manera general se puede decir que el mito, tal como es vivido en la sociedades arcaicas, 1) constituye la historia de los actos de los seres sobrenaturales; 2) que esta historia se considera absolutamente verdadera (porque se refiere a las realidades) y sagrada ( porque es obra de los seres sobrenaturales; 3) que el mito se refiere siempre a una "creación", cuenta cómo algo ha llegado a la existencia o cómo un comportamiento, una institución, una manera de trabajar, se han fundado; es ésta la razón de que los mitos constituyan paradigmas de todo acto humano significativo... " (Eliade M ircea, A spectos del Mito", pag.27).

El estudio se desarrolló en Copán Ruinas, municipio que en la actualidad cuenta con 67 aldeas y 37 caseríos, según el Censo de Salud del 2001 la población total asciende a 31,324 habitantes, de Ios cual es un $58 \%$ vive en pobreza extrema y el IDH 0.369 inferior al del departamento que se calcula un IDH 0.430. Según información de la encuesta de $\mathrm{H}$ ogares el $77 \%$ de la población vive en zona rural y el 23\% está en la zona urbana, la población rural la mayoría es de origen maya-chorti, población que se encuentra distribuida en un total de 19 aldeas. La población maya-chorti asciende a 5,114 habitantes distribuidas en 18 aldeas, la población femenina alcanza la cifra de 2,608 que representa el $50.9 \%$

\section{EL SABER DE LAS PARTERAS Y LA RELACIÓN CON LA PRÁCTICA MÉDICA.}

Las parteras son mujeres, que trabajan con el nacimiento, con la vida en contacto directo con las mujeres, este rol les significa una relación de poder e influencia sobre la fertilidad y fecundidad de éstas. Las percepciones de ellas nos dan cuenta de la relación del valor sobre la vida, la maternidad. A cercarse a esta cosmovisión es un proceso de reconocimiento de resistencias, símbolos y significados.

A I inicio del trabajo en el grupo focal y en la entrevista a profundidad el interés fue de reconocer como válidas las prácticas médicas de la profesionalización de parteras, que realiza el centro de salud y auscultar y explorar un aparente desconocimiento y desvalorización de sus prácticas tradicionales.

La discusión inició con un grupo de 14 parteras, todas se conocen y se ve un ambiente de respeto y alegría por el encuentro, parece que las diferencias entre indígenas y mestizas es muy tenue, su identidad como partera es la definitoria. El inicio es marcado por las mujeres del pueblo que orientan la discusión hacia una validación del conocimiento médico y un desconocimiento de sus saberes y sus practicas culturales, las expresiones en el grupo lo denotan:

"a veces porque ellas se sientan mal entonces ellas lo mandan a llamar a uno, y uno va, a decirle pues que si se siente mal yo la controlo y después le digo que vaya al centro que allí le van a decir qué es lo que tiene, y les digo vayan al centro y hablen con la doctora porque solamente ella sabe qué es".

Se les preguntó: si las mujeres no pueden ir al Centro de Salud, que tipo de atención les dan ustedes, la respuesta?

Pues si es que tienen que venir, si porque ya uno no puede más por ellas, uno no sabe, verda, mientras que los médicos saben.

En la entrevista con doña Tiba, partera indígena del C hocó, la actitud inicial fue similar, se tuvo que realizar un mayor acercamiento para facilitar la confianza, encontrar el conocimiento de las mujeres. Doña Tiba nos dice al principio:

P. Y cómo atiende los partos usted?

R. - A h, yo así acostaditas, si así es ajá

No mire solamente así cuando ya les llega la hora ellas están acostaditas y por la voluntad de D ios salen bien.

P. - $\quad Y$ les dan algo de tomar

R. - Pues así cuando se tiene que guardar las muchachas sí, se les da un remedito para que agarren calor en el cuerpo.

P. - Y qué remedio les dan

R. - Yo solamente la manzanilla

Doña Tiba en esta parte de la entrevista esta validando el conocimiento recibido en las capacitaciones del $C$ entro de Salud, donde si es aceptada la manzanilla como medicina natural y la atención en el parto es acostada.

En susprácticas en atención, repiten al inicio el discurso de las capacitaciones dadas en el centro de salud:

"E llos pueden recetarle porque entre veces uno sabe que lo tiene que hacer todo eso, pongamos nosotros yo creo que todos nosotros las comadronas nos dieron unas hojas, de que en esa hoja donde está la mujer embarazada, ya uno ya luego yo eso es lo que hago no sé si mis compañeras lo harán verdad, yo les reviso los ojos, le miro el color a mi paciente, le pregunto cuántos años tiene, luego pues ya vengo yo y lo apunto en un papelito donde están las mujeres embarazadas, ya las mando a control, a que me le saquen sangre, la vacunas, yo todo eso yo lo hago con mis pacientes, mi amor vaya al centro por sus vitaminas queremos, no sabemos si es (...) entonces solo la doctora lo puede hacer.

... y todas lo mismo porque a veces ellas sienten molestias, les agarra bolencia o algo así, entonces les digo yo que es bueno que vengan porque ellas les puede dar vitamina o cualquier cosa les puede dar porque uno, nosotros eso no lo conocemos.

Las parteras manifiestan que existe una resistencia de las mujeres a asistir a la atención médica.

Doña Tiba manifiesta: "...estamos qué hacen ellas mejor me muero, se pueden morir porque y qué les espera, si nosotros deberamente que cuando venimos aquí venimos apren der al go no se nos queda todo, somos mentirosas si decimos que todo se nos va a 
quedar, pero a nosotros nos han dicho que de cuatro hijos arriba ya necesitamos que nos operen, también mayores de 35 años, o de 20 años abajo verda que son de 13, 14 años esas cipotas no se pueden asistir verda, pero son tan necias prefieren morirse que ir al hospital, por qué lo harán?".

La resistencia que existe para asistir a los centros es el temor a ser esterilizadas, porque en la capacitación dada a las parteras se recalca esta información.

Cuando profundizamos más en la conversación aparece un reconocimiento fuerte al saber delas mujeresy el valor de sus prácticas tradicionales:

Yo gracias a D ios que cuando voy a atender un parto estoy llena del saber, yo me consiento muy contenta y ya me voy para la casa. yo cuando me toca una mujer de parto, cuando ella ya está libre, ya estoy libre yo también de ir a mi casa, porque ya estoy, ya defendí aquella paciente con su niño, ya luego preparado a los tres días le digo yo: vaya ahora báñese bien bañadita y le voy a pegar la masijeada, ya le doy la calentadita y aquella tranquila.

A I reconocer su saber aparecen las prácticas tradicionales como válidas y a pesar de las capacitaciones realizadas las practicas culturales tradicionales son las que prevalecen en la zona.

\section{II: COMO SE INICIARON COMO PARTERAS}

La iniciación como partera en la mayoría del grupo fue por herencia materna o de la abuela, hay casos planteados como revelación por sueños, es una apuesta a la recuperación de la genealogías femeninas, en los sueños quien aparece es una mujer dando las indicaciones, mujer asociada a la deidad femenina, en el caso de lasindígenas y deidad masculina en caso de la mestizas.

"ah, ya, y al principio cómo hacíamos, yo mi D ios me dio el entendimiento, yo no he aprendido ya ahora después fue que ya nos dieron, verda, yo ya traiba, cuando uno trae esa cencia en de que ya $D$ ios verda le alumbra la mente para darle ese trabajo a uno. a saber por quéserá eso que por medio de sueños así verda, a mi nadie me dijo también de que eso iba a ser".

... mi mamá era partera, buena partera era..

" ah y yo mi mamá no sabía nada mi abuelita era que era comadrona, la mamá de mi mamá, yo donde ella iba me llevaba, porque uno andaba de sacón, verda y yo ponía cuidado".

Esimportante rescatar que la su experiencia como madres esta presente en su oficio de parteras.

"Si este don me lo dio en un sueño mire que me obligó la mujer que la partiara aquella mujer se me aparentó que era una mujer desconocida viera era una mujerona alta, vestido blanco y me obligó que lo hiciera aquella mujer y yo lo vide y tuve que hacerlo y yo le decía que ya estaba y me decía que le faltaba no volví hacerle yo entonces vaya hoy si y estaba así tiene que seguir.

"Yo no aprendí yo solamente $D$ ios y la virgen me dio este don mire y yo me han llevado a los centros pero yo ya más todo los tenía ya mire porque yo ya vía asistido bastantes mire, cuando me quemaron, mire, esa señora Julia me quemó que yo era partera y que no iba a. . . me pidieron al centro y yo estoy viniendo y ya nos llevaron hasta Santa Rosa mire.

$\mathrm{H}$ ay dos aspectos importantes que rescatar en las expresiones de sus experiencias: una que no es un aprendizaje conciente, sino que es un DON otorgado por una divinidad o por herencia de mujeres y en la capacitación en los centros es considerada la experiencia parcialmente.

\section{III: VOCACIÓN DE SERVICIO}

La vocación de servicio hacia la comunidad es una de las actitudes fuertes que las parteras tienen y expresan con un rasgo de su identidad personal; es notorio como el nacer y el servicio están a la comunidad forman parte de un solo cuerpo. Existen diferencias entre indígenas y mujeres urbanas mestizas. Las parteras urbanas cobran y las indígenas tiene otra relación con el servicio que brindan.

. ". . pues de mi persona nacer de uno verdad, nacer es pongamos yo como partera, visitar mi comunidad, platicar con mi gente verda, mire contarles lo que vamos hacer en el centro de salud, mire que tal cosa y bueno platicar con ellos verda, de lo que yo más o menos he estado y ya pues mi gente ya ellas ya queda conformes yo también ya me voy conforme para mi casa digo yo bueno está bien eh, ir hacer, pongamos ir a visitar mis enfermos llevarles algo allí medicinitas y hacer algo, para mí es que de mí ha nacido ir a visitar aquella gente, eso es un nacer para mí no sé verdad.

Si, uno se desvela toda la noche y todo un día y ha veces no le ofrecen ni un trago de café ni un pedazo de tortilla con sal, pero uno no les pide bueno, uno agradece aquella tortillita con sal con hambre se la come porque toda la noche sin dormir un ratito uno agradece.

"yo, hasta ahora voy hablar, yo en mi aldeya yo a las pacientes así para sobar y todo me preguntan cuanto les voy a ganar y yo les digo lo que sea su voluntad, esa es mi palabra lo que yo tengo en mi aldeya, lo que sea su voluntad mire ve, no le pongo precio verá porque allí lo que sea la voluntad de ellos, y si no le dan nada, allá el Dios de arriba le ayuda a uno, porque ya el día llegado allá, ellos tan pobres pero ellos quedan bien vaya como es que no va a ganar tenga, un puñito de frijoles, un atado de dulce, gracias compadre me lo dan que yo lo lleve.

Las parteras urbanas tienen una percepción diferente sobre su oficio y la valía en términos económicos.

"yo cuatrocientos cobro, porque nosotros el doctor E rasmo dijo que nosotros las parteras teníamos que ponerle un precio al parto y hasta muy poquito cobramos se acuerda lo que nos dijo que hasta muy poquito cobrábamos".

"N o yo allá en mi aldeya ay pasamos nosotros así, no como yo ya varios me tienen confianza, de dicha tengo dos a mi cargo tienen más confianza con uno y hay una primeriza pero ella está viniendo aquí, tal vez está postrada uno la ve, pero si uno no puede aunque sea 
su tortilla con su poquito de chilate cocido, porque eso si le dan a uno"

"Ya de ellas de su voluntad ya le dan a uno algunos 50 pesos, pero es gratis, eso es voluntad de ustedes, o algo así, no lo más que me dan a mi aunque sea unos 20 pesos, pero ahora si cobro, yo ya este año como 17 partos he atendido bien, solamente uno me dio 100 lempiras y otro 50."

"A mi todos mis partos que yo he atendido a mi nadie me queda mal, para qué yo voy a decir que no me pagan, como no si me pagan pero eso si llegan a mi casa y me dicen Canducha fíjese que yo si necesito que me inyecte, anoche mellegaron dos, yo necesito que me pinche, está bien Luz yo tengo mi caja para inyectar, yo los inyecto, alcohol y algodón y todo" .

"eso es como así hacemos nosotros cuando criamos la señora que fue mi partera nunca ella me dijo tanto le voy a ganar, pero yo con mi concencia sabía que al ajustar la dieta allá liba dejar su tortillitas paguito de unas sus tortillas."

"C omo antes verda decía que negocio hacía uno, ahora es que está cara la vida, ella tuvo en posada mire y ya ve que ni le querían dar posada antes de tener su niño, en eso la gente de antes como había que atender a todos así es que se gana uno, es que hay gentes que son pobrecitas, ay a esos pobrecitos mejor ayudarles verda y si uno tuviera más apoyo mejor llevarles, si una vecina".

"Ellos no, a veces si quieren me regalan más de una mi cosita con ellas así yo con eso me conformo, porque pobrecitas tal vez tienen varón verda pero qué la pobre criatura no train dinero ni nada sino que sino que en oro vienen los niños me da lástima real mente y yo no les gasto. A sí dicen pero yo no les gasto ni varón ni hembra, ni particular si yo he ido a ver particular yo no les gasto, si hay veces que son conscientes y solo me regalan unas mis pollas grandes para que los coman yo con eso me conformo."

La pobreza de las mujeres y su familia es la que determina la relación de pago por los servicio de parto, existe una relación de empatía entre la situación de partera y de la comunidad. Es notorio que esto ha determinado cambios en las prácticas cultural es de mayor valía

\section{ATENCIÓN A LAS MUJERES EMBARAZADAS}

R egularmente las parteras inician a atender a las mujeres a los tres meses de embarazo A partir de ahí ya se quedan controlándolas, hasta que se llega al parto.

\section{De tres a seis meses de embarazo}

Según lo plantean las parteras, los problemas que las mujeres enfrentan en este período de embarazo están relacionados con la actitud emocional de la mujer frente al embarazo.

Los problemas comunes en las mujeres son: dolor de cabeza, hinchazón en los pies, las mujeres padecen de desgano, sueño, hay a quienes los pies se les hinchan y los ojos se ponen amarillos y sufren de pesadez en el cuerpo.

0 tros de los problemas señalados cuando empieza al primer mes sienten ansiedad y cuando van teniendo más meses van sintiendo malestar en el estómago, dolores de cuerpo.

Ya de los seis meses sienten frío hasta paludismo les dá, hay unas que sí, hay unas que se afligen cuando se dan cuenta que están embarazadas, se afligen y lloran y se decepcionan, hay quienes dicen hay mejor no me viera casado yo.

También suceden esas cosas de que también se les sube la presión, o se les baja la presión, tal vezpor eso es que ellas se sienten mal así, tristes con ganas de llorar.

"O tras que se ponen tristes, demasiado, yo eché deber una que desde que salió embarazada con náuseas, ella no comía, sino que solo cositas así de verduras verda, comer no hasta que ella ya fue ajustando cuatro meses es que ya ella empezó a comer ya bien normal, antes no comía, digo yo que uno hay quienes que salen bien verda, están embarazadas no sienten ningún problema y el muchacho si sienten malestar."

Las parteras dicen que las mujeres se resi sten a asistir a control en el centro de salud, ellasles recomiendan que se controlen pero la actitud de las mujeres es la de no hacer caso", que si les dicen a ellas no hacen caso, hay unas que se están hasta dos meses sin asistir al centro y otras nunca asisten".

Las que van a control, tienen resistencias a tomar las medicinas que le dan en el centro aduciendo efectos secundarios tanto en el embarazo como en el parto. "si, las vitaminas les digo yo, pero dicen muchas que yo no voy a tomar las vitaminas porque mire que muy gorda se va a criar el niño es lo que dicen a lora de la tenida me va costar, así me han dicho muchas a mi yo no me las bebo porque dicen que muy gorda, hay que tomar otras cosas verda".

Esta es una situación que las mujeres no están dispuestas a engordar para facilitar el trabajo del parto.

\section{Seis a nueve meses, antes del parto. Cuáles son los proble- mas que enfrentan?}

En este período de embarazo las mujeres enfrentan problemas de hemorragias y problemas relacionados con la posición en las que el feto se encuentra, que está de pie o sentado, según las parteras esto provoca hemorragias. O tro de los problemas es el ahogo, dolor de cabeza y vómito.

"Bueno, o sea las pacientes que llegan a la casa le dicen a uno usted qué será que a mi me duel e la cabeza, y fíjese que me dan ganas de arrojar, y fíjese que a mi la comida que me como a mi no me sustenta, y entonces también dice fíjese que yo siento al niño que se me hace así por un lado, siento como que me hoga así, qué será le dicen a uno, esas son preguntas que ellas hacen, también dicen, fíjese que yo siento que me pulla aquí mire a usted le señalan, esas son preguntas que ellas hacen verda, pero como ya el niño está de seis meses en adelante puede estar parado, puede estar sentado y otra cosa dicen cuando se me sale por aquí y por aquí también qué será 
usted, esas son preguntas que es cuan do el niño está atravesado, también dicen fíjese que otra cosa que si ento yo que parece que se me va a salir al go por la parte, de que estoy sangrando, ajá eso quiere decir una placenta previa verda."

U n aspecto importante en la parte emocional es el miedo a morir en el parto.

Entonces ahora vamosa la contestación cómo les vamosa contestar, porque si a mi me llega una persona y me dice fíjese que a mi me duele la cabeza, siento una depresión que yo quisiera estar solo acostada y que yo siento ganas de llorar de irme le dicen a uno bien preocupadas verdad, hay quienes hasta Iloran adelante de uno de sincera será que me voy a morir, será que me voy a morir qué dice usted le dicen a uno,

se está tomando la vitamina, no fíjese que a mi me da basca, y las vitaminas que las hizo, hay las tengo, o sea así como me las dio la doctora así las tengo, y porqué no se las toma, pues fíjese que me dan basca, y mire que cuando me tomo la vitamina me acuesto y me duermo todo el día, mire que tremendo

para que se dé cuenta que le tienen más confianza a uno, que a uno le van a decir todavía y será cierto lo que la doctora dice, porque yo si siento esa cosa que me ahoga fíjese, no pues es cierto está sentado, pero que me pulla aquí, son los piesitos está parado, ajá todas esas preguntas ellas se las hacen a uno, pero uno les dice que tien en que ir al hospital, yo he luchado con un montón de mujeres que si son necias porque ellas pelean con la muerte, eso ya es peliar con la muerte, mujeres que tienen ya 14 hijos a nosotros nos han dicho aquí que todas así también entonces todo eso para la embarazada es una gran cosa, vayamente cuando van de seis a nueve meses se necesita que ya mero se va a ver el producto que van a tener verda y todo eso entonces ya de seis meses a nueve también tiene que exigirles la vacuna, vacuna, examen de sangre porque esas son las enfermedades que están pegando verda, pero lo más importante que coman bien, beban bien y estén bien.

En el entrenamiento dado en el C entro de Salud a las parteras les han instruido para que alienten a las mujeres a que se alimenten bien, y que duerman bien. Las parteras enfrentan la costumbre de las mujeres que comen poco por no querer engordar según ellas dificulta el parto y por lo tanto se tienen que comer poco. Esto acarrea problemas de debilidad que les dificulta el trabajo de parto.

\section{Las mujeres se resisten a la atención hospitalaria "U NO LAS NECEA QUE SE VAYAN AL HOSPITAL PERO ELLAS SON CAPRICHUDAS."}

Es complejo convencer a las mujeres para que reciban atención médica hospitalaria, las rutinas hospitalarias, las dietas, los exámenes que les practican están en contra de su cosmovisión, al gunas prefieren morir.

" 14 hijos con ese, no quiso irse para el hospital lloraba a mares, una dejación hasta que se gravó por el tumor, porque por el tumor si se gravó, tal vez no tendrá más, porque el tumor lo botó pero allí está di otro, pero a nosotros claramente esa gente así no estamos responsables asistirla, pero dejarlas morir no se puede".

"A h, y qué podemos hacer nosotras con las mujeres caprichudas, qué podemos hacer, mire porque hay veces que hasta les dan un papel para que se vayan y esperan a dar luz la criatura allí y como ya D ios quizá les ayude y lo tienen bien y una mujer le pasa de darle allí y no va y aunque uno lo mande dicen en el hospital por eso no voy yo, mire seño dicen, yo por eso no voy al hospital, me train arroz, huevo, mantequilla y mandarlo a bañar otro día a uno usted que se muera, yo no me quiero morir horita yo tengo mi montón de hijos y con agua helada quieren que uno se bañe y le dan de comer aquel platote como no son ellos que se van a enfermar, yo por eso yo no voy al hospital, ah y como hace uno, no se puede. "

O tras de las resistencias están en relación a los exámenes médicos que les practican, no existe una explicación por parte de las/os médicos el sentido y las consecuencias que esos exámenes tienen, según las parteras los que las mujeres le expresan es lo siguiente:

"a principios si porque nadie quería hacerse el chequeo de embarazarse, no de simple porque ellas dicen para qué le sacan sangre a uno, para qué lo pullan a uno, eso es lo que dicen ellas, caso si antes a nadie pullaban dicen a nadie le sacaban sangre para qué le sacan sangre no ve que hasta váguido le da, para que le dan ese montón de pastillas, si antes uno no bebía pastillas, mi mamá tuvo veinte hijos y no se bebió nada de remedios."

"E sa era y por eso ya nosotros si estamos dispuestos si ir a pegar al hospital más luego nos arruinamos allá, porque allá nos van a dar cosas que nos van a arruinar."

En estas prácticas encontradas lo que está en juego es la vida de las mujeres, es necesario replantear el acercamiento desde un reconocimiento de las resistencias y significados que existen en torno a la asistencia en salud y desde otras sensibilidades reconocer que existe razón y verdad en sus prácticas.

\section{LA LUNA ES LA PRIMERA QUE TOCA A LAS MUJERES}

A la luna en diferentes cosmovisiones se le atribuye poderes mágicos de protección constituye la representación del amor y de lo cíclico de la existencia de las mujeres.

Para las comadronas chortís, la luna es la que determina los ciclos de fertilidad y fecundidad de las mujeres, determina la mestrución o regla, la concepción, el embarazo, el aborto, el parto.

La mestruación es la enfermedad de luna, dicen que cada mes toca la luna a las mujeres y debido a eso sangran. La luna es la primera que toca a las mujeres y es la primera que tiene que tocarlas.

La luna se mete hasta para asistir partos, el día que viene o el día que se va la luna se enferman, en cuarto de ocho también se enferman y en luna llena también.

Se cree que los días de luna es peligroso para las enfermedades y es la que determina el sexo: "y se va la luna o sea en los días de luna hay peligro vea, cuando está llena la luna también los niños se enferman, y cuando está llena la luna dicen que es varón" 
Los efectos de la luna cuando hay eclipse son varios, principalmente en el embarazo, puede dañar al feto provocán dole malformaciones, dicen que le come o le pone un dedo, y por lo tanto se necesita protección, es necesario que la mujer embarazada se proteja con un cordón rojo, debe ponerse un blumer negro con ropa roja y llevar anillos de oro.

"pues yo cuando el eclipse pues si hasta peineta roja me ponía " porque la peineta no se la quitan ni de dia ni de noche

\section{LOS DESEOS DE LAS MUJERES, UN MIT O?}

Los deseos de las mujeres en el embarazo, la mayoría son comidas accesibles, pero es riesgo de no complacerla perjudica a la niña/o.

Los deseos comunes de las mujeres:

- pacayas crudas

- dulcitos de esos de leche

- moronga

- elote

- manguitos verdes

- chepes con lorocos

- limón con sal y pimienta

- chile chilpepe

- flor de izote con sal

- pepemechin

Los riesgos que las mujeres tienen si no cumplen sus deseos es que puedan abortar.

0 tros problemas que existen en las niñas/os cuando no se cumplen los deseos:

- Los niñas/os nacen con la lengüa de fuera.

- Con alergias en la piel,

- Con formas de los deseado.

- $\quad \mathrm{N}$ acen con labio leporino

PARTO

En la definición que presenta Victoria Sau: "fenomenológicamenteel parto es aquel hecho por medio del cual se pone de manifiesto de forma irrevocable que una mujer está poniendo en el mundo a otro ser, así como que dicho ser ha nacido de dicha mujer y no de otra. El parto tiene lugar diez meses lunares después de haberse producido la fecundación. En la antigüedad, y todavía en los pueblos primitivos, el parto era asunto exclusivo de mujeres y los hombres no tenían acceso al mismo." (Sau Victoria, P. 227).

Para las mujeres en estudio el parto sigue siendo una acción vital exclusiva de mujeres don de no hay acceso de los hombres. Esta definición existencial choca bruscamente con la atención hospitalaria, donde generalmente son hombres los que atienden.

Existe un reconocimiento de que los partos no todos son iguales, plantean que, hay partos normales y partos costosos. Los principales problemas que las parteras identifican en el parto:
- $\quad$ el problema de la mujer cuando está en el parto es que le caiga sangrado.

- $\quad$ pero como hay chiquitos así como decimos nosotros hay chiquitos que vienen en seco eso da seña la mujer unos ligones blancos y aquella agua, así es unas no somos todas.

- $\quad$ si, aquella agua y agua y ya cuando es seña que ya viene aquella liguita que bota con sangre, ya va venir dice uno y ya al reventar aquella cosa viene la criatura.

- doble o sea que la placenta no salga luego eso es un problema, la placenta se tarda mucho eso tiene peligro.

- el otro problema que hay después del parto que la placenta llega a los cinco minutos

- la placenta está pegada, así dicen, unos dicen que porque está pegada, así dicen, porque algunas se asolean cuando lavan dicen y de eso se les pega verda.

- $\quad \mathrm{N}$ iños todas atravesada o que estén muertos

\section{LA ATENCIÓN EN EL PARTO}

\section{YO SOLO ME PONIA ASI MIRE, HINCADA COMO ASI ME EN SEÑ ARON}

Para las mujeres y parteras chortis, es imposible pensar que puedan parir acostadas, sus prácticas les demuestra que es fácil el parto si lo realizan hincadas. Ellas como parteras han tenido todos sus hijos en esa forma, nos lo confirma doña Tiba:

$\mathrm{H}$ incada mire es mejor y con una cosa mire doble debajo, si es mejor tenerlos así porque yo no sé yo nunca tuve un hijo acostada, si los tuve mire y era cayendo y uno los pepenaba y era la chiche y de allí decía lo amarraba con hilo y le metía la tijera y ya estaba lo demás me iba acostar a la cama y pepenaba lo demás lo envolvía y destapaba la puerta para que entrara el hombre, porque ni el hombre quería que estuviera junto a mí, ya con esto yo me atendía, solita yo me servía.

En la descripción que realizan del parto, la mujer embarazada está hincada con un pequeño banco, para que pueda sentarse cuando se sienta cansada, la partera está en la parte de atrás sostenién dola con sus dos manos la zona del tórax.

Por detrás los detiene, aquí de aquí los detiene uno, es cuando dicen que le está dando uno valor a una paciente y de allí sentada, ya ande se cansa entonces uno siempre los levanta el cuerpo y uno se sienta en un trocito mire, pero acostadas no aguantan estas mujeres de aquí aunque uno les diga acuéstense no aguantan, mejor así, de otra forma no lo pueden tener, no.

A Igunos partos se complican, las mujeres no logran expulsar la placenta, el procedimiento que utilizan es colgar a las mujeres de una viga, que queden en total posición vertical que les ayuda a la expulsión de la placenta.

$\mathrm{Si}$, el hombre me lo detuvo lo colgué mire y se lo eché y no lo quise que lo acostara luego así sino que yo estuve sobándolo y sobándolo y lo amarré bien hasta que lo amarré bien lo dejamos que se acostara entonces le dije acuéstese de lado, buena mire aquella señora criando bebé, y le 
dimos remedio se compuso y luego yo le dije aquel señor y no me la va a dejar moler luego hasta los dos meses, de cuidar y la mujer siempre cría

La partera nos describe un parto difícil, argumentando que el problema es que la mujer inició el trabajo de parto acostada y nos relata lo siguiente:

"E ste, yo todos los partos han salido bien, solamente una me espantó una vez mire y estaba yo recién aprendido, por eso digo yo que cuando le quiere pasar una desgracia a una mujer le pasa, esa señora lo tuvo acostada porque dice que ella tuvo una comadrona y así le enseñó ella solo acostada los tenía, y cuando me mandó a llamar a mí yo llegué, yo que llego y tuvo la niña acostada y lo demás no le venía, y ella no era inteligente no me contó, mire 24 horas estuvo aquella mujer y ella no me decía mire y de allí le dije yo la voy a sobar le dije yo y dije a recogerle no le tantié nada mire ay con el gran poder de Dios si usted no tiene nada y dónde lo tiene le decía yo qué usted y ella no se quería ya se moría ella y ella no me quería decir mire, y como le dije yo que no era por repararlo ni por nada y solo lo pensé yo mire y me contó él cómo estaba la cosa y vaya ayudanos y el hombre solo arrimado vaya ayudarme porque esa mujer se muere y de allí con aquella aflición y valor y algo de miedo de ver aquella mujer como estaba ah dije yo que le hiciera un ciu solo era un poco de sajar mire dicen que la mano de uno es peligroso mentiras y si no teniendo pieza uno en la mano por la gracia de D ios y a la virgen como ella me dio ese don mire ella me ayudó y lo colgué y se lo eché."

\section{EL POSTPARTO "LA SOBADA SÍMBOLO DE PROTECCIÓN HACIA LA MUJER"}

El cuidado, la protección, de la vida de las mujeres es una de las prioridades que se realiza a través de sobar el cuerpo, usando aceites aromáticos, el lugar donde se cierra es la zona de la reproducción y sexualidad de las mujeres.

"A h, si yo la sobo bien sobadita para que queden protegidas, así es y ellas me dicen que quedan tranquilas con la sobadita que uno les da.

$C$ on dos masijeadas que se les pega para que queden protegidas, porque si uno no las soba a esas mujeres no quedan tranquilas pues, hay que pegarles la masijeadita para que esté lo más normal.

a los ocho días. A los tres días se pega una bañada, al solo ajustar los ocho días se pegan otra bañada uno los va a sobar de vuelta ya quedan ellas protegidas, ellas quedan bien agradecidas que uno les cuide su vida"

La partera en el posparto juega una papel de acercamiento y cuidado sistemático y permanente; algunas parteras se trasladan a vivir a la casa de la mujer hasta que cumple la dieta de los 40 días.

\section{Las medicinas naturales no son malas, no les hacen mal a nadie}

Existen tés que se suministran antes del parto, en el parto, y después del parto, las primeras tienen la función de acelerar la dilatación, la que se toma después del parto es para que las mujeres recobren el calor en el cuerpo y las siguientes tomas son para limpieza del cuerpo.
Después del parto toman agua de pericón, alucema y romero.

U n choque enorme entre el parto atendido en el H ospital y la atención en la casa es la referida al baño, en la atención del hospital las mujeres deben bañarse al siguiente día con agua fría, según su aprendizaje este debe realizarse hasta los nueve días y con agua de remedio.

Las hierbas y raíces que usan son:

- $\quad$ yerba grande se usa la raíz.

- yerba del toro

"Pues yo nosotros, aquí de veras mire como somos natural, nosotros hasta los nueve días se bañan las muchachas, y si no nos bañamos como en el centro que ya a los tres días los bañan, porque nosotros aquí aprendimos así aprendimos como lo hacen allá y aprendimos como porque fíjese que dicen que allá en el centro no usan eso, no usan estas cosas, y la faja que les pone uno aquí mire después de tener a los tres días y por eso no nos bañamos luego porque a los nueve días se bañan. "

También es importante en el postparto que las mujeres sean sobadas y fajadas y existen recomendaciones de no realizar al gunas actividades domésticas.

Y fíjese que nosotros al bañarse mire las muchachas a los nueve días se bañan, siempre se les pega otra juntada y amarrada la faja, ellas muelen, barrer si no barren, ni jalan agua sólo pueden moler y tortear y las muchachas quedan bien.

El juntar es sobar con azajar que en es un ungüento o pomada caliente, que se arregla de manteca de cuche, se pone frirse y se recoge todos los remedios y se le echa que esté hirviendo y se cuela en un trapito, y queda la pura mantequita, color verde. Se le echa flor de lima o flor de naranja flor de café y manzanilla, yerba del toro, santo domingo y currimiento, pericón, alcanfor.

\section{LAS DIETAS Y CUIDADOS DE LAS MUJERES EN EL PARTO}

En la concepción de estas mujeres el parto es húmedo por lo tanto los al imentos deben de ser secos, el parto es frío y la selección de alimentos deben ser calientes, su alimentación durante cuarenta días es de tortillas tostadas, gallina asada y queso bien seco y la carne de vaca que esa es buena comerla porque es carne caliente, la carne de cerdo es fría por lo que no debe comerse.

Las dietas que tradicionalmente han sido usadas en el periodo de post-parto son consideradas en las capacitaciones como no necesarias, pero la tradición es fuerte y las mujeres siempre guardan sus dietas, tanto en sus alimentos como es sus hábitos de limpieza cotidiana.

Pero ellas lo que más comen es gallina dorada y tortilla con 0 sea que arreglan el poco de sal, muelen la sal le echan chile o pimienta o cominos a esa sal y si no hallan queso ni gallina eso están comiendo y su taza de pinol con dulce, toman simple, porque el azúcar no la usan porque es muy helada; manifiestan no toman agua hasta después de los 40 días. 
L as parteras dicen que es difícil cambiar lo hábitos de las dietas en las mujeres, y es más complejo en las que tienen ya varios hijos. "Verdad, entonces los hábitos que uno tienen son difíciles de cambiar, o sea no es fácil eso verdad, a veces es importante que uno, bueno uno tiene que partir siempre de uno para poder entender porque también uno es resabido.

Las bebidas que acostumbran:

Solamente pinolito de maiz tostado mire se hace el pinolito se echa en el comal aquel pinolito y unos le dicen pinol blanco y medio como de chilate y lo muel en y le echan chile mire y dicen a beber y otro pinolito bien de maiz pero hacemos de café para que le abunde la leche a uno y bebemos café mezclo.

\section{A mamantar}

Para amamantar las parteras juegan un papel importante, deben preparar a las mujeres, primero les dan un masaje, porque los problemas que enfrentan es que algunas mujeres tienen los pecho rojos y no tienen pezón. Es necesario el masaje para que salga la calentura del pecho.

Las bebidas que acostumbran es el atol de maíz crudo y pinol con chile.

Las primerizas son las que enfrentan mayores problemas en el amamantar, presentan problemas de pezones hundidos, a los cuatro meses de embarazo se los revisan y si están hundidos, se los sacan y aunque no los tenga hundido siempre se hace el tratamiento para que cuando ya va a dar de mamar los pezones estén blandos. En este proceso ponen al compañero de vida a que les mame los pezones para que salgan.

0 tra de las cuestiones que consideran primordial es poner al niño desde que nace a mamar.

El procedimiento que explica la partera es la siguiente: "pues yo de lo que soy partera cuando mi paciente no le ha bajado la leche y en veces la niña o el niño quiere mamar lo que hago es untarle aceite y juntarle la mama solamente de aquí y la vena mayor más altita en la venita mayor que uno tiene aquí eso es nada más y ya cuando ya miro yo que ya le está bajando inmediatamente pongo al niño, eso hago de lo que yo soy partera verda ".

es bien dura y se le inflama la piedra, por eso es que tiene congestión.

El médico lo que dice que se cuecen tres conchitas de tilo con azúcar y el tecito se les da mientras la leche baja para que no tengan cólico.

las conchitas de zapote también son buenas mire es buena para bajar la leche, también mire se cuecen los manojitos de manzanilla eso es bueno mire.

cojollo de camote

las conchas de ajonjolí dorado, eso es para la madre que no le baja leche que tienen los pechos que ni los aguantan ya.

N o hay como la santa maría, Dios es el úlltimo, a pues la santa maría con dulce, mire dándole y le baja. eso es lo que dice el médico y su salud y él lo que dice que para el recién nacido se pone a mamar dice pero no a dejarlo que va jalarlo, entonces se hacen tres conchitas de pito con azúcar dice, se cuela el agua y de allí se les pone el pepito o con una gasita también se les está dando, pero es para mientras baja la leche, sale bastante dice.

eso hasta uno agarra comer cojollos de las florcitas para agarrar sueño. También la semilla de ayote la flor es bueno, entonces le agarra sueño a uno.

\section{ATENCIÓN A LOS RECIÉN NACIDOS}

Las parteras atienden a los recién nacidos y sobre su salud tienen algunas creencias como son el pujo, la caida de la mollera, el ojo.

\section{EL PUJO EN LAS-OS RECIEN NACIDOS}

El pujo en los recién nacidos es provocado por las mujeres, si éstas están mestruando y chinean al recién nacido, otra de las situaciones que provoca es que alguien venga de trabajar muy sudado y esa energía es trasmitida y se enferma o un hombre que anda enamorado o ennoviado.

Para curarlos se les dan chupones de culantro con anís, salvia, ponen a masticar a otra persona.

0 tra de las formas es chinear, untarle sudor y se le pone un pelo en secreto.

U no de lostratamientos más efectivos es " una niña y le ponen al niño en la faldita y le ponen y le ponen a mecerse los saumerios, los saumerios los hacen de hoja de limón, trenza de ajos, montes, para cuando el niño está pujoso que no se le quita con nada, entonces dicen que para eso es.

\section{LA CAIDA DE LA MOLLERA}

La mollera cuando se cae provoca diarreas y vomito en los recién nacidos, el tratamiento que se le aplica en palabras de la partera es la siguiente:

"A que se les caye la mollera y a eso al bañarse entonces uno lo ajunta bien mire y le chupa la mollera y le chupa las costillas mire y le brinca la mollerita y le queda brincando, si eso es lo que le hace uno pa que los niños dejen de ensuciar a cada rato, eso es lo que les hace uno".

Le hemos levantado así pa rriba y le chupamos y con este dedo le levantamos así mire el cielo de la boca y le chupamos de la mollerita y de las tetitas y eso es lo que le hacemos al chiquito, y nosotros si ya le digo que si aprendimos pero yo no estoy iendo aprender al centro, sino que yo ya D ios la virgen me dio este don.

\section{HACER OJO}

La-os niñas salen afectados por al gunas personas que tienen mirada fuerte, les hacen ojo que se manifiesta con granazón en todo el cuerpo y con mal olor.

Para curarlo es con guaro y con hoja de limón y hoja de ruda y 
lo bañan en todo el cuerpo. Y el que cura tiene que estar sudado, soplarlo y pasarle un huevo para limpiarlo.

\section{Planificación Familiar}

yo miro que hay gente que tal vez dos hijos y ay pero tener la retajila.

Según las parteras, las mujeres consideran que es pecado planificar y es difícil que acepten, se vive un tiempo remembrando el pasado.

U n aspecto importante que consideran para la decisión de la planificación está en relación directa con la mortalidad infantil, lo expresan de la siguiente manera:

"y allí aunque uno se muriera uno pero luego a esta gente que ya uno le preguna que ya tuvo de catorce, le dice uno pero los tiene todos, ya tengo tantos enterrados y por qué, porque no pues no tuvo cuidado, casi la mayoría la mitad se entierran o la cuarta parte.

"yo tuve más de la docena de hijos y siete se me criaron y siete se me murieron y allí está mire uste cosas de Dios mas bien ya, yo no asistía porque mi mamá ella era la que me asistía a mi no era por dejaciones ni nada, solo nacían las criaturas mire morados morados y de allí ya se morían siete mire, y si tuviera toda esa familia de hijos."

Las parteras no sienten la fuerza para poder influir sobre la decisión o convencimiento de las mujeres para que planifiquen la familia, ya que hay una.

\section{CONCLUSIONES}

Las prácticas cultural es de las mujeres y parteras indígenas son radicalmente opuestas a la medicina alópata, en sus concepciones, su lenguaje, su prácticas y creencias.

- Para ellas es el ser parteras no solo es un apren dizaje sino que es un don otorgado para la divinidad o por genealogías femeninas.

- El embarazo y el parto es asunto de mujeres, no conciben la presencia de hombres.

- A si mismas las parteras indígenas se consideran y se nombran comadronas.

- En la atención del embarazo, para ellas es necesario aten der la parte emocional, losmiedos, las dudas y enfrentar con las mujeres embarazadas el miedo a la muerte.

- El momento del parto que a mi parecer es el más complejo de encontrar una intercepción es la forma de parir incadas y en el hospital es acostada.

- Las dietas son rigurosas para ellas, el parto es húmedo y frío, necesita alimentación seca y caliente.

- $\quad$ Es necesario hacer un diseño de formación que no niegue sus creencias y prácticas, sino que las retome y a partir de ahí construir lo que sería un nuevo conocimiento y dará paso a nuevas prácticas sincréticas. 